Supplement of Geosci. Model Dev., 13, 859-872, 2020

https://doi.org/10.5194/gmd-13-859-2020-supplement

(C) Author(s) 2020. This work is distributed under

the Creative Commons Attribution 4.0 License.

(c) (1)

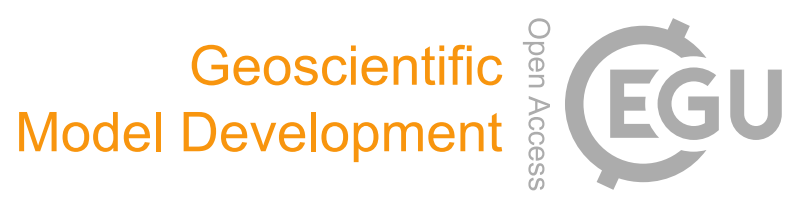

Supplement of

\title{
Uncertainties in climate change projections covered by the ISIMIP and CORDEX model subsets from CMIP5
}

Rui Ito et al.

Correspondence to: Rui Ito (rui.ito@jmbsc.or.jp)

The copyright of individual parts of the supplement might differ from the CC BY 4.0 License. 
Table S1: List of CMIP5 GCMs used in CORDEX.

\begin{tabular}{|c|c|c|c|c|c|c|c|c|c|c|c|c|c|c|}
\hline Model / Region & 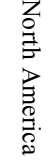 & 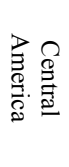 & 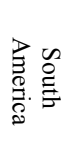 & 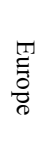 & 畕 & $\frac{3}{3}$ & 茟: & 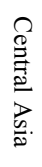 & 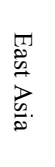 & 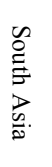 & $\begin{array}{l}\stackrel{2}{>} \\
\stackrel{1}{>}\end{array}$ & 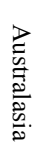 & 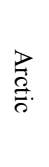 & 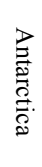 \\
\hline ACCESS1.0 & & & & & & & & & & 0 & ○ & $\bigcirc$ & & 0 \\
\hline ACCESS 1.3 & & & & 0 & & & & & & & & 0 & & \\
\hline BNU-ESM & & & & & & & ○ & & & & & & & \\
\hline CCSM4 & & & & 0 & & & & & & O & O & $\bigcirc$ & & $\bigcirc$ \\
\hline CMCC-CM & & & & & 0 & & & & & & & & & \\
\hline CNRM-CM5 & & 0 & & O & ○ & $\bigcirc$ & ○ & & $\bigcirc$ & O & ○ & 0 & & 0 \\
\hline CSIRO-Mk3.6.0 & & 0 & 0 & O & & & & & & 0 & O & 0 & & \\
\hline CanESM2 & 0 & 0 & $\mathrm{O}$ & $\mathrm{O}$ & & & 0 & & 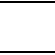 & 0 & O & $\mathrm{O}$ & 0 & \\
\hline EC-EARTH & 0 & 0 & 0 & 0 & & 0 & 0 & & $\bigcirc$ & 0 & 0 & $\mathrm{O}$ & 0 & 0 \\
\hline FGOALS-g2 & & & & & & & & & 0 & & & & & \\
\hline FGOALS-s2 & & & & & & & 0 & & & & & & & \\
\hline GFDL-CM3 & & & & & & & & & & 0 & & 0 & & 0 \\
\hline GFDL-ESM2G & & & & & & & ○ & & & & & & & \\
\hline GFDL-ESM2M ${ }^{\dagger}$ & 0 & 0 & 0 & 0 & & 0 & 0 & 0 & & 0 & & & & \\
\hline GISS-E2-R & & & & 0 & & & & & & & & & & \\
\hline HadGEM2-AO & & & & & & & & & $\bigcirc$ & & O & & & \\
\hline HadGEM2-CC & & & & & & & & & & & & 0 & & \\
\hline HadGEM2-ES ${ }^{\dagger}$ & 0 & 0 & 0 & 0 & 0 & 0 & 0 & $\bigcirc$ & 0 & 0 & 0 & $\bigcirc$ & & 0 \\
\hline IPSL-CM5A-LR' & & & & & & & & & & 0 & 0 & & & \\
\hline IPSL-CM5A-MR & & 0 & 0 & 0 & ○ & & ○ & & & 0 & & & & \\
\hline MIROC-ESM & & & & & & & 0 & & & & & & & \\
\hline MIROC-ESM-CHEM & & & & & & & 0 & & & & & & & \\
\hline MIROC5 ${ }^{\dagger}$ & & 0 & 0 & 0 & & & 0 & & & 0 & & 0 & & \\
\hline MPI-ESM-LR & 0 & 0 & 0 & 0 & 0 & 0 & 0 & & 0 & 0 & 0 & 0 & 0 & 0 \\
\hline MPI-ESM-MR & 0 & & & & & & & 0 & & 0 & O & & 0 & \\
\hline MRI-CGCM3 & & & & & & & 0 & & & & & & & 0 \\
\hline MRI-AGCM60 & & & & & & & & & ○ & & ○ & & & \\
\hline NorESM1-M & & 0 & 0 & 0 & & & 0 & & & 0 & & 0 & 0 & 0 \\
\hline
\end{tabular}

$\uparrow$ denotes the ISIMIP2b model. 


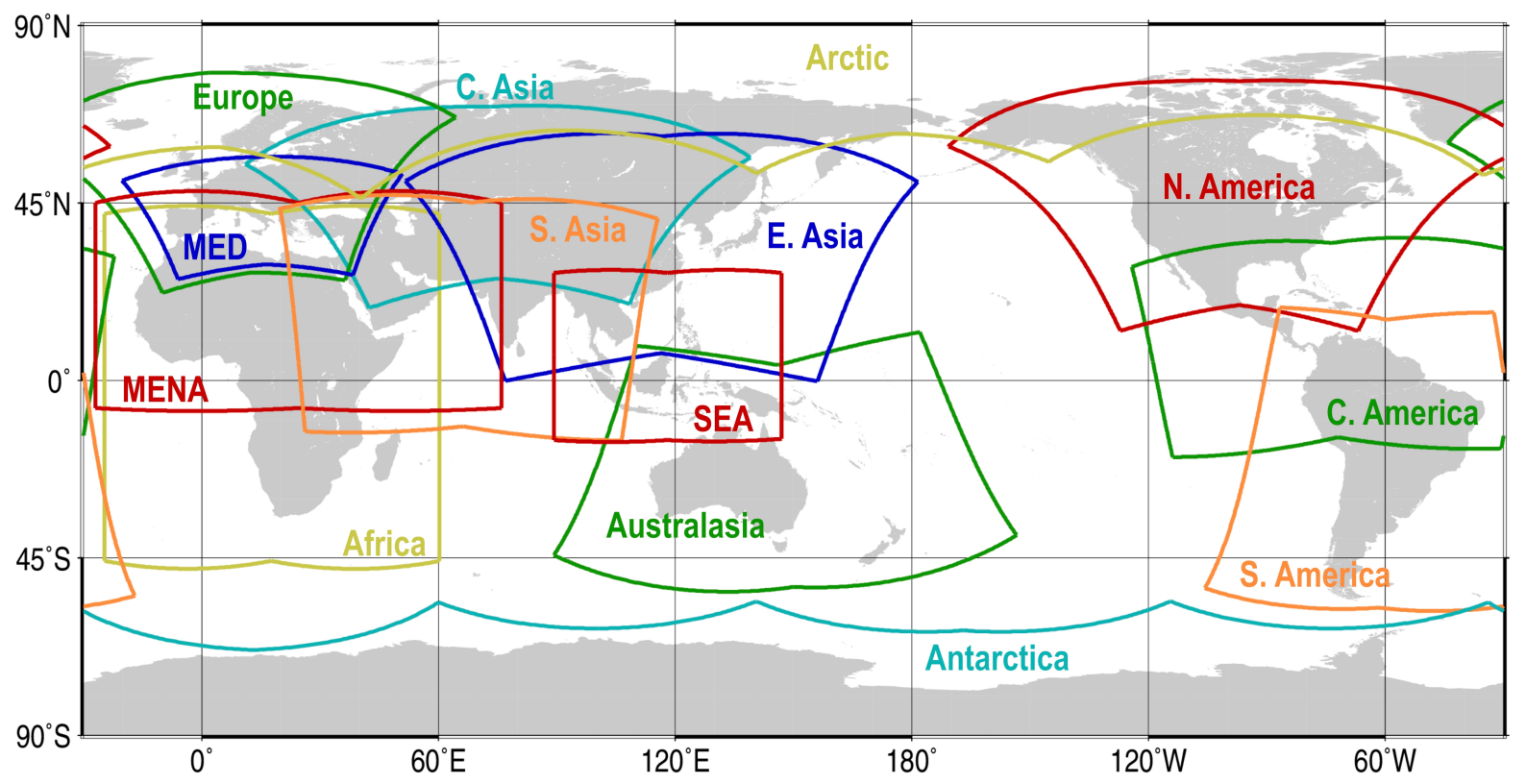

5 Figure S1: Regional classification defined in CORDEX. (Coordinate information is available from: http://www.cordex.org/domains/; last accessed 8 Nov. 2018). 


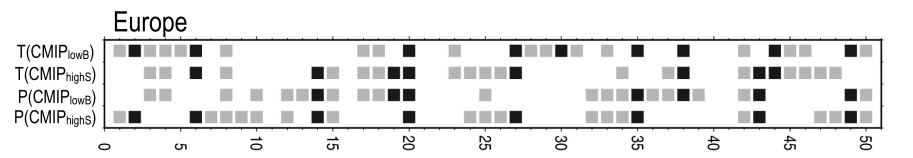

Southeast Asia
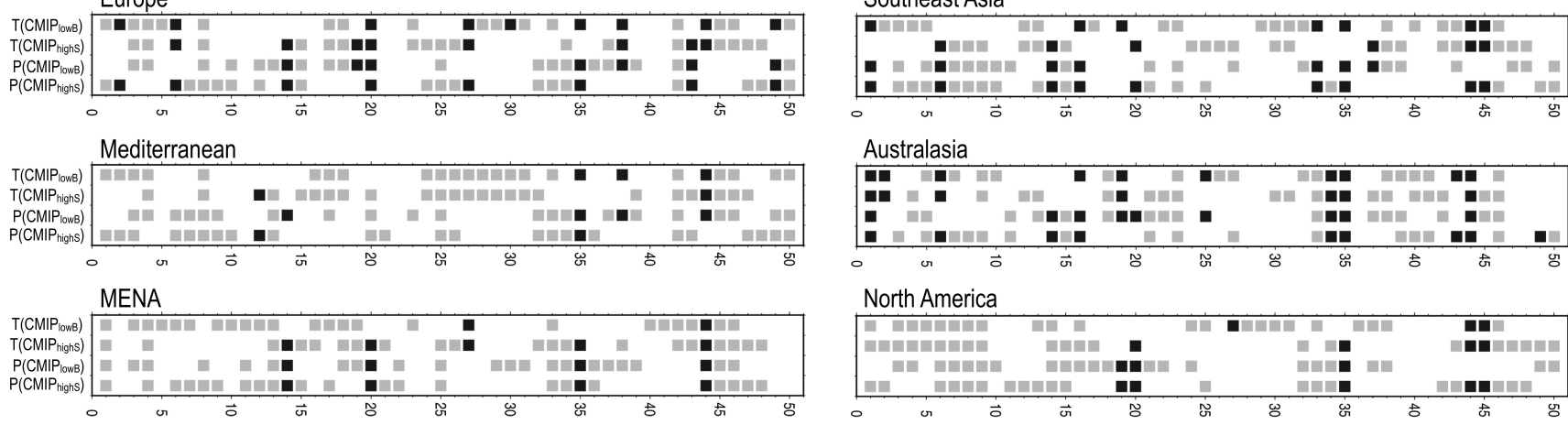

North America
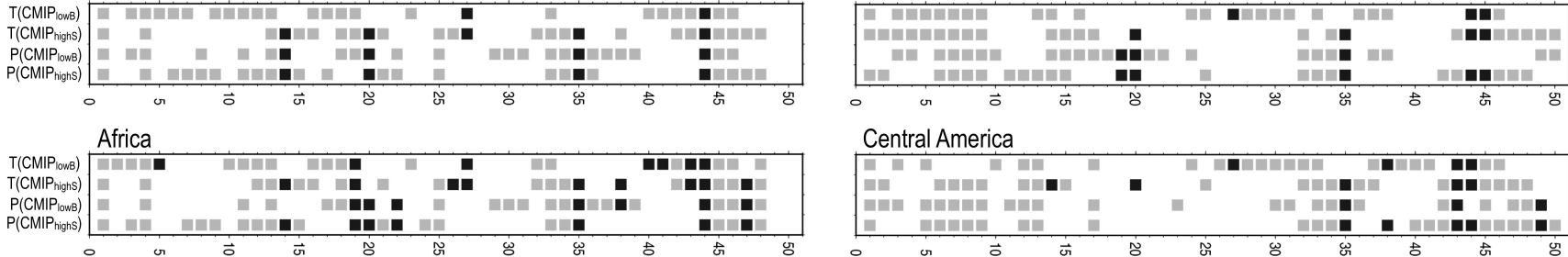

Central America
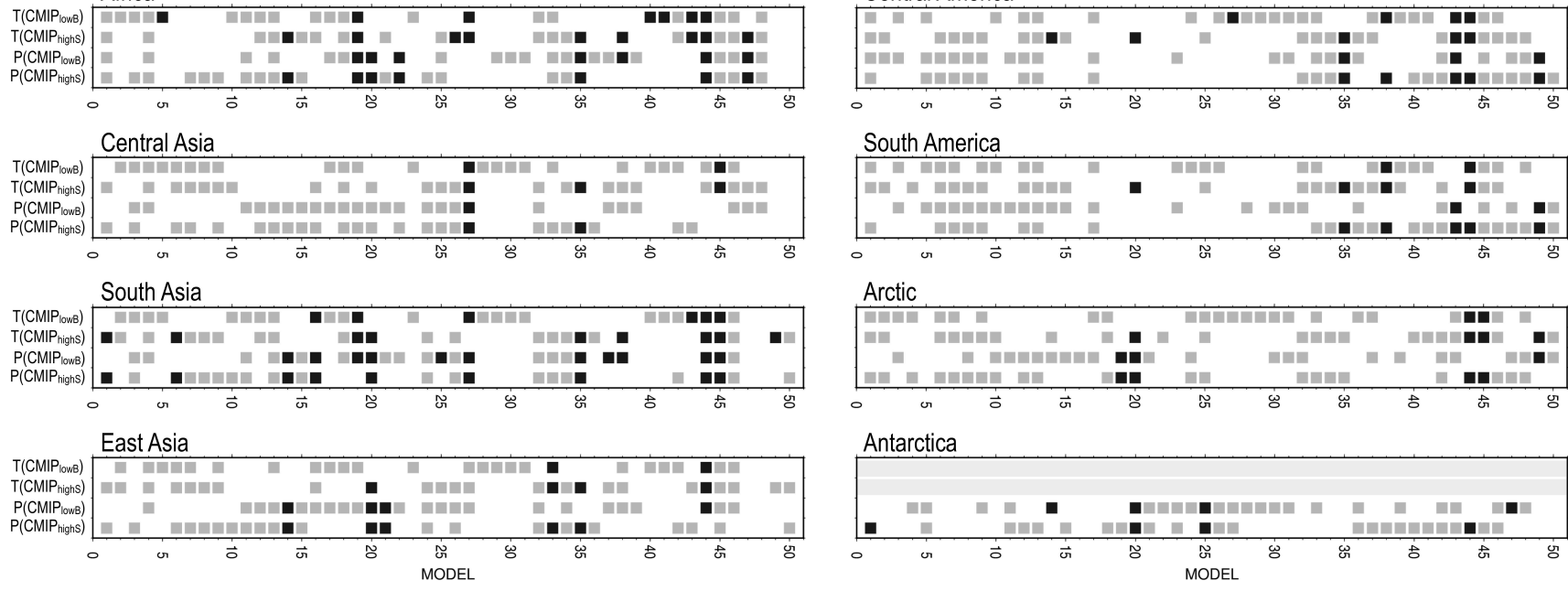

\begin{tabular}{|c|c|c|c|c|}
\hline $\begin{array}{l}1 \text { ACCESS1-0 } \\
2 \text { ACCESS1-3 } \\
3 \text { bcc-csm1-1 } \\
4 \text { bCC-CSm1-1-m } \\
5 \text { BNU-ESM } \\
6 \text { CCSM4 } \\
7 \text { CESM1-BGC } \\
8 \text { CESM1-CAM5 } \\
9 \text { CESM1-FASTCHEM } \\
10 \text { CESM1-WACCM }\end{array}$ & $\begin{array}{l}11 \text { CMCC-CESM } \\
12 \text { CMCC-CM } \\
13 \text { CMCC-CMS } \\
14 \text { CNRM-CM5 } \\
15 \text { CNRM-CM5-2 } \\
16 \text { CSIRO-Mk3-6-0 } \\
17 \text { CSIRO-Mk3L-1-2 } \\
18 \text { CanCM4 } \\
19 \text { CanESM2 } \\
20 \text { EC-EARTH }\end{array}$ & $\begin{array}{l}21 \text { FGOALS-g2 } \\
22 \text { FGOALS-s2 } \\
23 \text { FIO-ESM } \\
24 \text { GFDL-CM2p1 } \\
25 \text { GFDL-CM3 } \\
26 \text { GFDL-ESM2G } \\
27 \text { GFDL-ESM2M } \\
28 \text { GISS-E2-H } \\
29 \text { GISS-E2-H-CC } \\
30 \text { GISS-E2-R }\end{array}$ & $\begin{array}{l}31 \text { GISS-E2-R-CC } \\
32 \text { HadCM3 } \\
33 \text { HadGEM2-AO } \\
34 \text { HadGEM2-CC } \\
35 \text { HadGEM2-ES } \\
36 \text { inmcm4 } \\
37 \text { IPSL-CM5A-LR } \\
38 \text { IPSL-CM5A-MR } \\
39 \text { IPSL-CM5B-LR } \\
40 \text { MIROC-ESM }\end{array}$ & $\begin{array}{l}41 \text { MIROC-ESM-CHEM } \\
42 \text { MIROC4h } \\
43 \text { MIROC5 } \\
44 \text { MPI-ESM-LR } \\
45 \text { MPI-ESM-MR } \\
46 \text { MPI-ESM-P } \\
47 \text { MRI-CGCM3 } \\
48 \text { MRI-ESM1 } \\
49 \text { NorESM1-M } \\
50 \text { NorESM1-ME }\end{array}$ \\
\hline
\end{tabular}

Figure S2: Models with the top 50\% of the CMIP5 models for the model bias and Taylor's skill score in each CORDEX region. The numbers on the $\mathrm{x}$-axis correspond to the individual model number in the bottom box. The $y$-axis denotes the models with low bias 5 and with high score for temperature $\left(\mathrm{T}\left(\mathrm{CMIP}_{\text {lowB }}\right)\right.$ and $\left.\mathrm{T}\left(\mathrm{CMIP} \mathrm{P}_{\text {highs }}\right)\right)$ and for precipitation $\left(\mathrm{P}\left(\mathrm{CMIP} \mathrm{P}_{\text {lowB }}\right)\right.$ and $\mathrm{P}(\mathrm{CMIP}$ highs) from the upper to the bottom. Gray square indicates the models fit the condition on the $y$-axis and black square indicates the inclusion in the CORDEX subset. Light gray bar in Antarctica indicates the missing data because of missing the CRU reference data. 


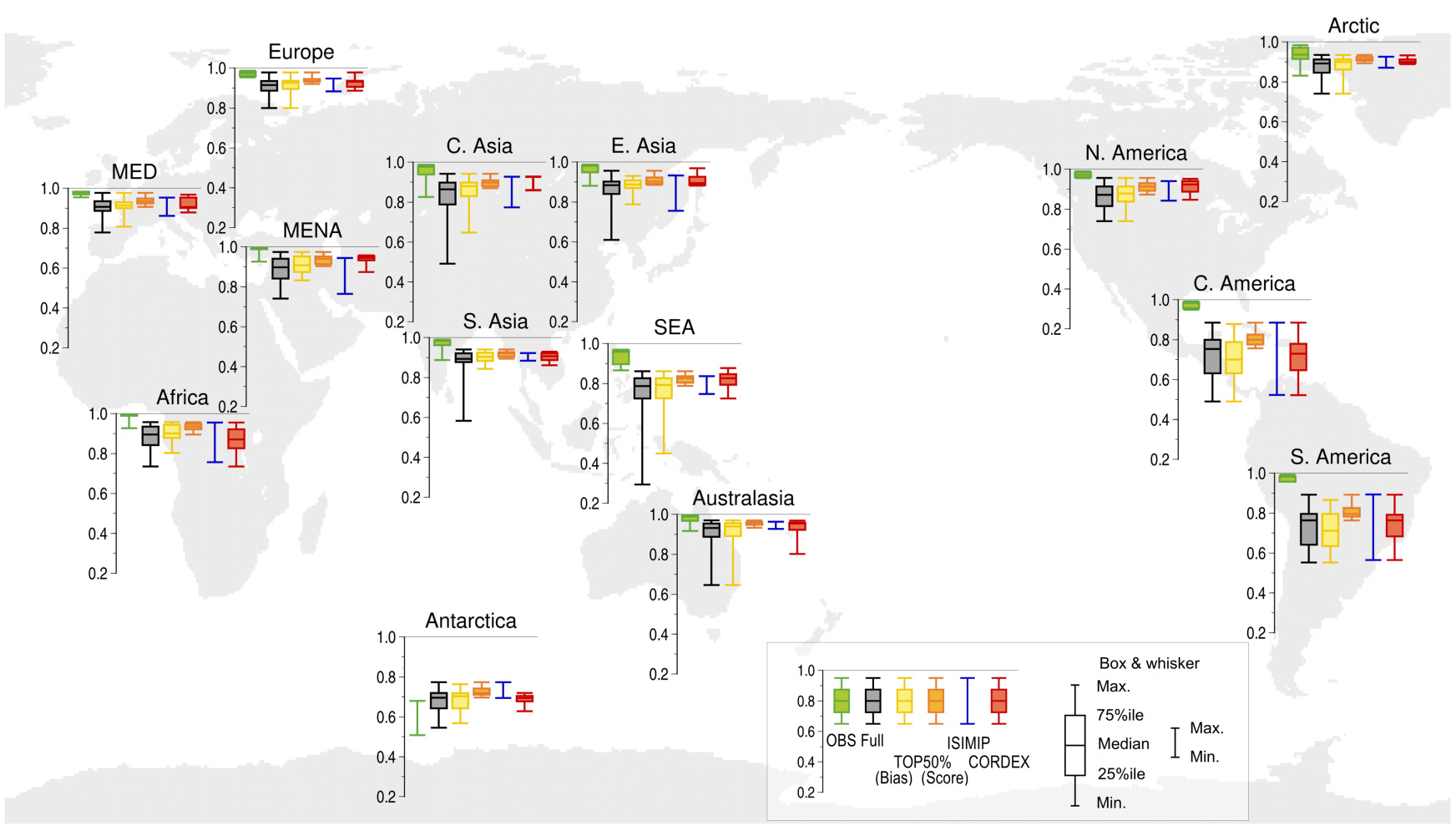

5 Figure S3: Skill score for annual mean model precipitation over land. Reference data are from GPCC. The whiskers of the box plots show the range between the maximum and the minimum scores. The boxes and the lines within the boxes indicate the 25 th to 75 th percentile range and the median, respectively. Green plots indicate the spread of the scores of six observed data: CRU, CPC, PRECL, CMAP, GPCP and MSWEP. The other plots indicate the score in the full set of 50 CMIP5 model set (black), the model sets with the top 50\% of the CMIP5 models for the model bias (yellow) or the score (orange) and the model sets selected for ISIMIP (blue) and CORDEX (red). 


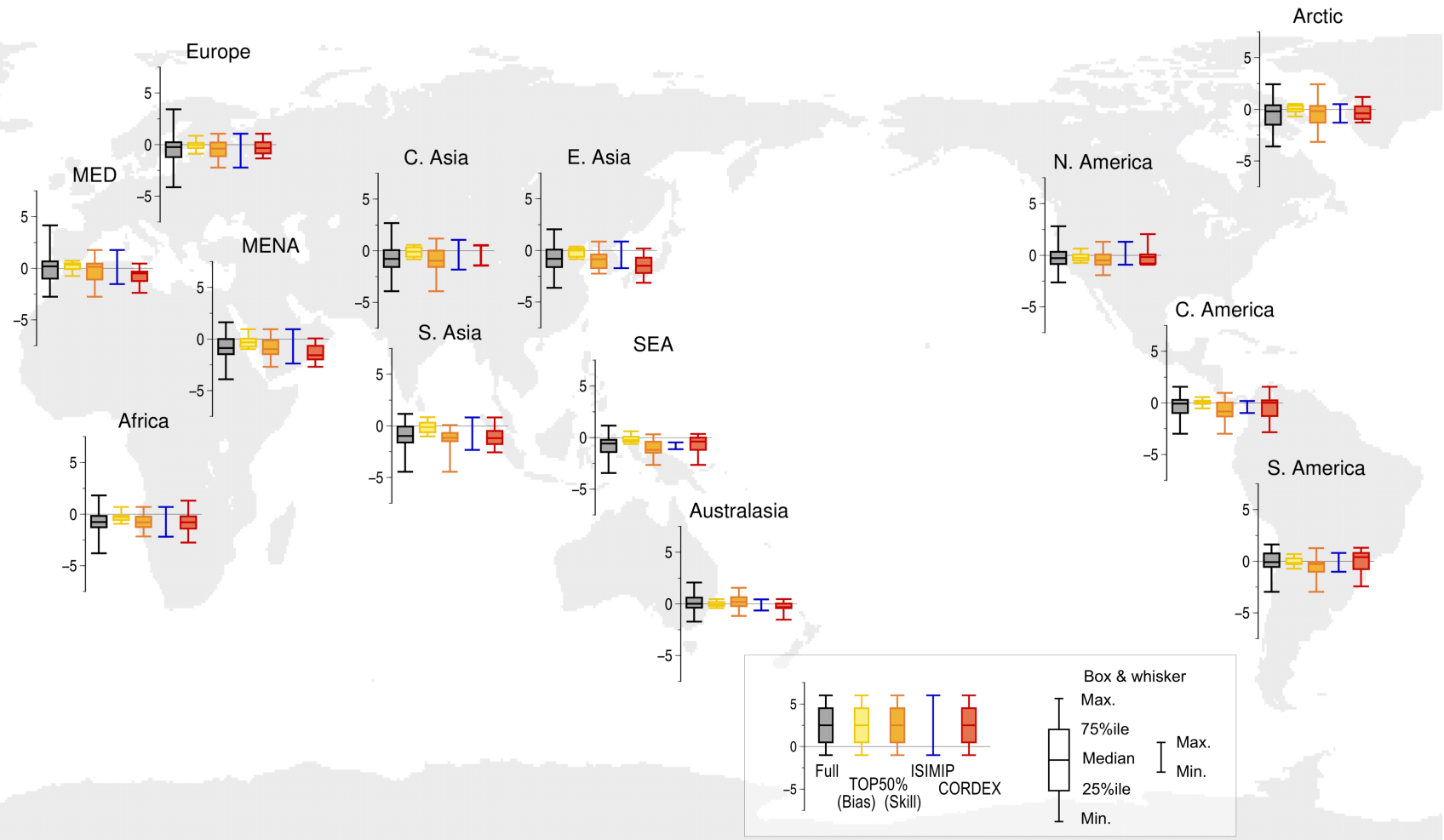

5 Figure S4: Annual mean model temperature bias over land (K). Reference data are from CRU. The whiskers of the box plots show the range between the maximum and the minimum biases. The boxes and the lines within the boxes show the 25 th to 75 th percentile range and the median, respectively. The other plots indicate the model bias in the full set of 50 CMIP5 model set (black), the model set with the top $50 \%$ of the full set for the bias (yellow) or Taylor's skill score (orange), and the model sets selected for ISIMIP (blue) and CORDEX (red). There are no plots over Antarctica because of missing the CRU reference data. 


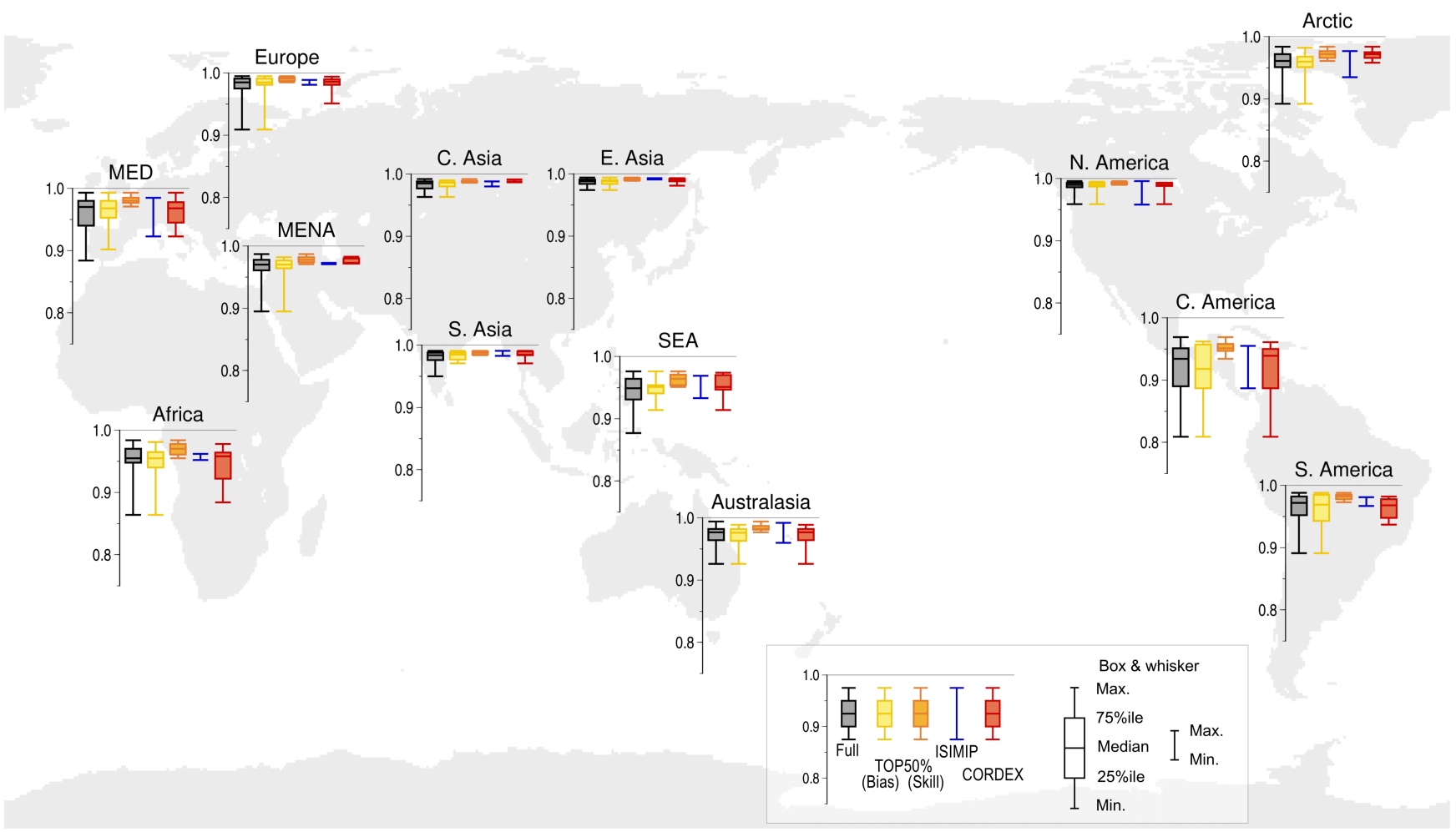

5 Figure S5: As for Figure S3, but for the annual mean model temperature over land. There are no plots over Antarctica because of missing the CRU reference data. 